
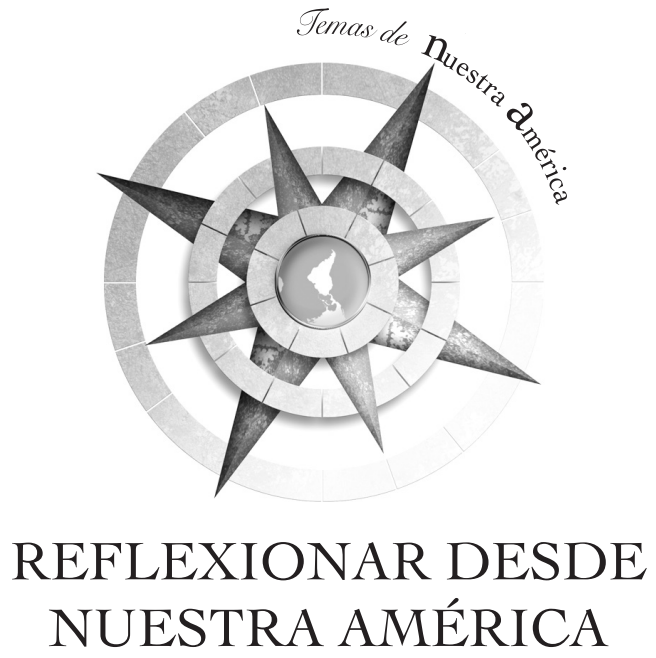



\title{
La literatura de la Región Norte Costarricense. Un caso paradigmático: Francisco Rodríguez-Barrientos
}

\author{
Literature of The Northern Zone of Costa Rica. A \\ Landmark Case: Francisco Rodríguez-Barrientos
}

\section{A Literatura Da Região Norte Da Costa Rica. Um caso Paradigmático: Francisco Rodríguez-Barrientos}

\author{
Adriano Corrales-Arias \\ Académico \\ Instituto Tecnológico de Costa Rica \\ DOI: https://doi.org/10.15359/tdna.35-66.1 \\ Recibido: 04/04/2019 \\ Aceptado:10/072019
}

\section{Resumen}

La Región Norte de Costa Rica ha sido poco estudiada en términos socioculturales y aún mucho menos en términos literarios. Sin embargo, a pesar de su escasa edad y desarrollo, es notoria la producción de esa región en cuanto a volumen y variedad literaria. Hay escritores consolidados que irradian ya no solo al resto del país, sino hacia la región centroamericana y más allá.

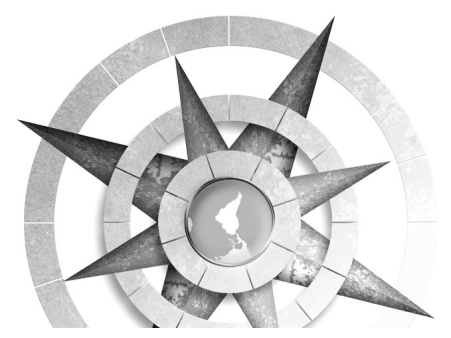

Dentro de esa producción sobresale la obra del sancarleño Francisco Rodríguez Barrientos, tanto por su amplitud de géneros como por la temática. Rodríguez Barrientos, hasta donde se conoce, es el escritor costarricense y centroamericano que, hasta ahora, ha producido la obra más amplia y profunda en un género poco frecuentado por escritores nacionales y contemporáneos: el aforismo. Además, en los últimos años ha dado a conocer parte de su producción narrativa, la cual asombra no solo por su rigor creativo, sino por su amplitud temática y escritural: dos libros de narraciones, tres novelas y una trilogía inédita. En este artículo se analiza esa obra, especialmente la narrativa, privilegiando una novela de características históricas, La sed de los días, en el marco de la literatura norteña, costarricense y centroamericana, como 
un aporte pionero en algunos géneros y como un planteo estético y de amplio espectro que coloca en el mapa literario nacional a la Región Norte. Es este uno de los aportes más visibles y denodados en cuanto al fortalecimiento de sus identidades y de su devenir sociocultural.

Palabras clave: literatura de la Región Norte costarricense; identidades; aforismo; novela costarricense contemporánea

\section{Abstract}

The North Region of Costa Rica has been little studied in sociocultural terms. Much less in literary terms. However, despite its short age and development, the production of this region is remarkable in terms of volume and literary variety. There are consolidated writers who radiate not only to the rest of the country but to the Central American region and beyond. One of the most outstanding works of this production is that of Francisco Rodríguez-Barrientos, from San Carlos, both for the wide range of genres and themes. He is, as far as we know, the Costa Rican and Central American writer who, up to now, has produced the widest and deepest work in a genre rarely frequented by national and contemporary writers: the aphorism. His recently released narrative production amazes not only for its creative thoroughness, but for its thematic and scriptural breadth: two books of narrations, three novels and an unpublished trilogy. This paper aims to analyze his work, especially the narrative work, privileging a novel of historical characteristics, La sed de los dias, [The Thirst of the Days], within the realm of the Northern, Costa Rican and Central American literatures, proposing it as a pioneering contribution in some genres and as an aesthetic approach and broad spectrum that places the northern region on the national literary map. This is one of the most visible and daring contributions in terms of strengthening their identities and their sociocultural development.

Key words: Northern Region Costa Rican Literature; identities; aphorism; contemporary Costa Rican novel.

\section{Resumo}

A Região Norte da Costa Rica tem sido pouco estudada em termos socioculturais e muito menos em sentido literário. No contudo, a produção desta região é notória em termos de volume e variedade literária. Há escritores consolidados que repercutem no resto do país, assim como na região da América Central e além. Dentro desta produção, destaca-se o trabalho de Francisco Rodríguez Barrientos, da cidade de San Carlos, tanto pela sua amplitude de géneros como pelo seu tema. Rodríguez Barrientos, pelo que sabemos, é o escritor costarriquenho e centro-americano que, até agora, produziu a mais ampla e profunda obra de um gênero raramente freqüentado por escritores nacionais e

12 La literatura de la Región Norte Costarricense. Un caso paradigmático: Francisco Rodríguez-Barrientos Adriano Corrales-Arias
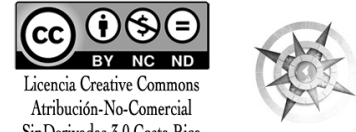

SinDerivadas 3.0 Costa Rica 
contemporâneos: o aforismo. Além disso, nos últimos anos deu a conhecer parte da sua produção narrativa, o que é surpreendente não só pelo seu rigor criativo, mas também pela sua amplitude temática e literária: dois livros de contos, três romances e uma trilogia inédita. Neste artigo pretendemos examinar esta obra, especialmente a narrativa, dando prioridade a um romance com características históricas (La Sed de los Días) no âmbito da literatura do norte da Costa Rica e da América Central, como uma contribuição pioneira em alguns gêneros e como uma abordagem estético e de amplo espectro que coloca a Região Norte no mapa literário nacional. Esta é uma das contribuições mais visíveis e vigorosas para o fortalecimento das identidades e desenvolvimento sócio-cultural desta região.

Palavras chave: Literatura costa-riquenha da Região Norte; identidades; aforismo; romance costarriquenho contemporâneo, literatura latino-americana

\section{Prolegómenos históricos y conceptuales}

La Región Norte de Costa Rica, por su conformación y colonización tardías, ha sido poco estudiada en términos socioculturales. Mucho menos en términos literarios. Sin embargo, a pesar de su escasa edad y desarrollo, es notoria la producción reciente de esa región en cuanto a volumen y variedad literaria. Si consideramos la misma en términos de sus publicaciones, encontramos que esta es prácticamente nula durante el siglo pasado. Aparte de algunas monografías históricas y tanteos de aficionados que no cuajaron en publicaciones, destaca la solitaria producción de la educadora sancarleña Margoth González López (Tapezco, Alfaro Ruiz, 1922- Ciudad Quesada, 1992), cuyos esfuerzos y aportes pueden considerarse pioneros, orientados hacia la literatura infantil. Hizo la educación primaria en Ciudad Quesada y la secundaria en la desaparecida Escuela de Perfeccionamiento Docente. Cursó estudios superiores en el también desaparecido Instituto de Formación Profesional del Magisterio. Laboró treinta y siete años como maestra rural. De su producción hemos podido ubicar el libro Poesía para niños (1979, Departamento de Publicaciones, Ministerio de Cultura, Juventud y Deportes, 62 p.).

Como digresión necesaria, es pertinente peguntarnos por las literaturas desde las diferencias identitarias que han construido regiones desiguales en un país como Costa Rica, inventado desde la centralidad: la colonización interna partió del centro hacia la periferia, exceptuando las regiones fronterizas y el Guanacaste. Claro que las diferencias identitarias existen a pesar de la homogenización cultural inducida desde el centro, por los liberales primero, por los socialdemócratas después y en la actual coyuntura por la globalización bajo el esquema neoliberal. Si, como 
lo ha planteado Benedict Anderson (1993), la nación es una "comunidad imaginada", entonces la identidad o las identidades son también "imaginadas". Siguiendo la lógica que sugiere el autor, supondremos entonces que al interior del país (Estado-nación) se dividen, o diferencian, territorios en el marco de aquella comunidad imaginada. Dicho de otra manera, a partir de ciertas particularidades se diversifican territorios o regiones reinventando comunidades imaginadas, aunque de dimensiones menores o supeditadas a la noción nacional. Es importante entonces tener a la vista que los territorios (regiones político-culturales), al igual que la nación, están atravesados por relaciones de poder, las cuales se imbrican con el Estado-nación y el sistema mundo global.

Ahora bien, la cuestión inicial debería ser: ¿Existe una literatura nacional? Y si existe, ¿quién o quiénes la definieron? Plantear que existen "literaturas regionales" dentro de una "literatura nacional" implica ya una acción de subalternidad; es un proceso de negación, a pesar de que, es evidente, las regiones culturales existen e interactúan en el plano nacional/internacional. Ciertamente se trata de cuestionar la visión "vallecentralista", o "vallecentrista", homogénea, horizontal y aclimatada bajo el concepto de "literatura nacional"; pero ello implicaría responder a las preguntas: ¿Cuál es esa literatura nacional, dónde se encuentra, cuál es su cronotopo? En cualquier caso, se trata de saber si hay un centro en la construcción de la "literatura nacional", y dónde se encuentra, o se encontraría, ese centro. De existir, entonces deben existir márgenes, y estar al margen, o en los márgenes, bien visto, podría ser una ventaja comparativa si se asume con rigurosidad y con un proyecto ideo-estético coherente. Pero estar en los márgenes no significa, necesariamente, estar en una de las regiones periféricas; se puede estar en los márgenes, o al margen, habitando y produciendo en el mismo centro.

La discusión deriva en otra interrogante: ¿Cuáles son las fronteras del Estado-nación? Mejor dicho, ¿Cuáles son las fronteras discursivas del constructo Estado-nación? O mejor aún: ¿Cuáles son los límites de la autoridad (icentral?), de su retórica, de sus instituyentes o del dispositivo sociocultural (Ministerio de Educación, Ministerio de Cultura, universidades, medios de comunicación masiva, editoriales, etc.)? De otra manera: ¿Cómo se expresan las relaciones de poder dentro de la "cultura nacional" y cuáles son los espacios de negociación, en caso de existir esos espacios? Y, si acaso los hubiera, ¿qué se negocia y quiénes negocian?

Lo "nacional" es ambivalente: por un lado, como ya lo señalamos, es un constructo, un discurso (una pedagogía, diría Homi Bhabha; 2010) y por otro, una vivencia cotidiana (una performatividad, según Bhabha). Por eso

14 La literatura de la Región Norte Costarricense. Un caso paradigmático: Francisco Rodríguez-Barrientos Adriano Corrales-Arias

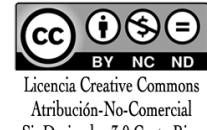


el discurso nacionalista, o la retórica del poder que origina ese discurso, produce escisiones, ambivalencias y vacilaciones. El discurso de la autoridad central genera su contingencia (su resistencia) porque ella misma, al enunciarlo, se coloca al descubierto como ideología. Debido a lo anterior, la "literatura nacional", o la "cultura nacional" ("la nación”, el "Estado-nación”), pasan de ser un símbolo discursivo al síntoma de un malestar, aunque no necesariamente generalizado. Ese malestar se expresa de diferentes maneras y se arraiga en los márgenes como una forma de resistencia discursiva ante la autoridad (el canon) y sus relaciones de poder. Ello sería claro para el intelectual y/o escritor (¿periférico?) que posea conciencia de una ideología que intenta homogenizar a la sociedad para "hablar" en su nombre.

"Lo regional" o particular en "lo nacional" implica entonces una tensión entre prácticas residuales y prácticas emergentes: hay una disputa por la autoridad narrativa, por el poder simbólico. Hay prácticas y significados que la cultura dominante (icentral?) no puede reconocer como reales, sino como deformaciones o rezagos temporales, o estructurales (folclor, primitivismo, naif, sub/subdesarrollo, etc.). Y hay otras (las emergentes) que en principio son combatidas, pero finalmente son incorporadas, o cooptadas, como parte del discurso hegemónico (el canon).
Así sucede, por ejemplo, con la poesía urbano/coloquial/antilírica y la narrativa también urbano/marginal/contracultural, casi siempre producidas en el Valle Intermontano Central.

Hechas las anteriores consideraciones téorico-metodológicas, veamos el "desarrollo" de la "literatura regional del norte". Tal vez la primera expresión, más o menos organizada en términos editoriales, sea la creación de la revista Trapiche (1983) en Ciudad Quesada, San Carlos. Dicha publicación dio a conocer a jóvenes poetas que iniciaban en el arduo camino literario. Los fundadores fueron Adriano Corrales Arias (Venecia, 1958) y Franklin Araya Gamboa (Ciudad Quesada, 1957); más tarde se les unieron otros jóvenes creadores, entre quienes destaca Francisco Rodríguez Barrientos (Ciudad Quesada, 1957). Trapiche fue una revista artesanal que, no obstante, marca en mucho el nacimiento de la literatura sancarleña y norteña en general.

Luego de finiquitada la aventura editorial de Trapiche, Francisco Rodríguez Barrientos y Adriano Corrales Arias editaron una nueva revista denominada Akbal (¿1991?), pero solo se editaron dos números. Durante los inicios de los años noventa del siglo pasado, Adriano Corrales Arias creó y sostuvo un suplemento literario en el periódico San Carlos al Día, donde se dio a conocer literatura local, nacional e internacional. 
Con el poeta alajuelense Jorge Arturo Venegas Castaing (1961-2010), Corrales Arias también editó, en el mencionado periódico, varios números del suplemento literario Correlibros.

En 1995 se edita el libro de poesía Tranvía negro del sancarleño Adriano Corrales Arias en San José (Editorial Alambique). En 1996, y con el mismo sello editorial, aparece el primer y único libro de poesía de Francisco Rodríguez Barrientos, Sobrevivencia del agua. Estas publicaciones marcarán el inicio de una fecunda cosecha literaria de ambos autores. En 1997 se publica el libro de cuentos Avatares (Imprenta San carlos) del profesor Fausto Rojas Rodríguez (San Rafael de Coronado, 1937-Ciudad Quesada, 2008). En 1998 se publica el primer libro de cuentos del también sancarleño Gerardo Campos Gamboa (San Vicente de Ciudad Quesada, 1952-San José, 2016), Marisol sí sabe por qué te quiere, Ernesto (EUNED). Dicha publicación también es el inicio de la fecunda labor literaria de este notable cuentista, cuya obra alcanza niveles de calidad inusitados en la literatura norteña y costarricense en general. Durante este período aparece la revista Fronteras (1995) editada por Adriano Corrales Arias, como medio de extensión cultural de la Sede Regional San Carlos del Instituto Tecnológico de Costa Rica. Se editan quince números y se dan a conocer nuevos nombres de creadores norteños. Es esta quizás la publicación más robusta que se ha desarrollado en la Región Norte; la misma circuló por Centroamérica y más allá, convirtiéndose en una suerte de punto de encuentro al concebirse como un proyecto cultural que realizó tres Encuentros Centroamericanos de Escritores (el primero en San Carlos - Santa Clara de Florencia- y Los Chiles, frontera norte, 1997) y dos de poetas nicaragüenses y costarricenses denominados La Frontera, además de diversos recitales, conversatorios, talleres y congresos de culturas populares.

El inicio del siglo XXI encuentra escritores consolidados que irradian ya no solo al resto del país, sino hacia la región centroamericana y de más allá. Además de los ya mencionados, destacan el cuentista Mauricio Ventanas (Ciudad Quesada, 1967) y el ensayista y narrador Álvaro Vega Sánchez (Alajuela, 1952). En ese período aparecen nuevos poetas en Ciudad Quesada; tal vez el más destacado sea Rafael Ángel Esquivel Solís, mejor conocido como Rafa, desaparecido muy tempranamente (1980-2007) y cuya obra queda inédita; en el 2016 se edita un cuadernillo con parte de sus poemas, denominado Bitácora (La Chifurnia, San Salvador). Recientemente, una poeta sancarleña, Lucía Paula López Gamboa, publica su primer libro de poesía, Otoño sin tabuies (Editorial Mirambell, 2018). Mientras tanto, más al norte, en Upala, se desarrolla un incipiente movimiento juvenil que organiza talleres literarios y 
cuya cabeza saliente es Javier Azofeifa; su producción se encuentra inédita.

\section{Un caso paradigmático}

Dentro de la producción anotada sobresale la obra del sancarleño Francisco Rodríguez Barrientos, tanto por su amplitud de géneros como por la temática. Rodríguez Barrientos, hasta donde se conoce, es el escritor costarricense y centroamericano que, hasta ahora, ha producido la obra más amplia y profunda en un género poco frecuentado por escritores nacionales y contemporáneos: el aforismo. Ha publicado doce volúmenes de este género. Además, en los últimos años ha dado a conocer parte de su producción narrativa, misma que asombra no solo por su rigor creativo, sino por su amplitud temática y escritural: tres libros de narraciones (Historias en-contradas, Plegaria por Gretchen Schrader y Retrato de familia, las tres del 2016), dos novelas (La sed de los días, 2016; Sombra errabunda, 2017) y una trilogía inédita (Malinconia). Poeta, sociólogo, ensayista, narrador, profesor e investigador del Instituto Tecnológico de Costa Rica en la Sede Regional San Carlos, sus publicaciones sobrepasan la veintena.

En esta comunicación se pretende conocer y analizar la obra de Rodríguez Barrientos, especialmente su narrativa, dentro de la cual se privilegiará una novela de características históricas: La sed de los días. Debe subrayarse que la mis- ma, como toda su obra narrativa, se ha publicado bajo el seudónimo de Celso Romano, mismo que nos recuerda al polémico, por anticristiano, filósofo griego del siglo II del mismo nombre. Se parte del hecho de que en el marco de la literatura norteña, costarricense y centroamericana su producción literaria es un caso paradigmático, tanto por su amplitud temática como por el impulso pionero de géneros como el aforismo y la novela, con un planteo artístico novedoso y de amplio espectro que coloca en el mapa literario nacional, centroamericano y de más allá a la Región Norte de Costa Rica. La obra literaria de este autor, en su conjunto, es uno de los aportes más visibles y denodados en cuanto al fortalecimiento de las identidades y del devenir sociocultural de dicha región, amén de su fortaleza estética.

\section{Memoria y novela}

La sed de los días inicia con un prólogo en el cual, a partir de una investigación antropológica "sobre los veteranos de la Guerra Civil del 48", conducida por el Dr. Alejandro Barquero y con apoyo de los historiadores Rubén Juárez y Beltrán Salas, tenemos la oportunidad de conocer y adentrarnos en los pormenores de la historia de vida de Teodoro Villegas Ulate, conocido como Teo, Doro y David, el último, seudónimo político durante la compleja Guerra Civil de 1948, expuesta con sus espesos errores, excesos y horrores. 
Teodoro nació en 1920 en San Isidro de Coronado en un hogar muy pobre y combatió en el bando del Gobierno durante la guerra civil del 48 -Teodoro era militante del partido Vanguardia Popular- Desempeñó los oficios más diversos: desde repartidor de carbón en Coronado a obrero de una siderúrgica en Puerto Ordaz, en el oriente de Venezuela, pasando por peón cañero y mecánico en un ingenio de Grecia, operario de la Compañía Bananera en la zona sur, botero en los caudalosos ríos del norte costarricense, en el San Juan y el Lago de Nicaragua, electricista de mantenimiento en un hotel de Caracas... En su infancia recolectó café en fincas de Guadalupe, Moravia y Curridabat junto a su padre. Y a su llegada a la capital venezolana laboró en la construcción. Y fue conserje y camillero en el hospital San Juan de Dios, un trabajo muy a propósito -o muy a despropósito, depende de la perspectiva- para un antiguo combatiente. Y, justamente, Teodoro Villegas siempre amó esta palabra, combatiente, y cuanto ella connota. Y esta palabra, según él, lo definía -quienes lean su testimonio le darán la razón sin chistar- (La sed de los días, Prólogo del Dr. Alejandro Barquero, pp. 8-9).

Bajo ese manto supuestamente académico, que justifica muy bien su tipografía, se desenvuelven los acontecimientos de una novela que hurga en las heridas abiertas por la contienda bélica durante el año clave de 1948. Rodríguez Barrientos, mejor dicho, Celso Romano, nos confronta con los horrores de la Guerra Civil costarricense de ese año y sus secuelas: fusilamientos, ejecuciones sumarias, aplicaciones falsas de la ley de fuga, persecuciones, torturas, violaciones de mujeres frente a familiares, asesinatos a mansalva, exilios, etc. Es decir, nos enfrenta a una realidad oculta y borrada por la historia y la historiografía nacional, léase oficial.

Asunto pertinente para esta comunicación es que, a partir y a través de la historia de vida de su personaje central, nos presenta el marco casi salvaje de la colonización de la "bajura" sancarleña y del norte de Costa Rica. Asistimos a la brutal experiencia del personaje aludido frente a un caporal, gamonal o, sencillamente explotador, violador y asesino (Isaías Reyes Campoamor, alias Cebú), quien administra su hacienda cual señor feudal, con siervos en vez de peones, y se permite el acoso y la violación de mujeres, así como la humillación y desvalorización de varones sin que nadie lo confronte o se le enfrente, dado que "maneja" a su antojo a las autoridades locales. Dicho personaje, al parecer tomado de algunos prototipos de la realidad sociohistórica, es matoneado y el lector, de alguna manera, lo agradece.

Esos acontecimientos, enmarcados en paisajes caribereños exuberantes y paradisiacos (hoy la deforestación ha 
acabado en mucho con ellos), más otras peripecias del trabajador/narrador, van cimentando la conciencia social y política de Teodoro, hasta que, de manera orgánica, termina militando en el partido Vanguardia Popular (Partido Comunista) cuando se desempeña como obrero en la United Fruit Company en el Pacífico Sur. A modo de digresión, se debe subrayar el ingreso de nuevos paisajes a la narrativa costarricense. Dicho de otro modo, la zona norte de Costa Rica ha sido poco frecuentada por nuestra novelística; hay atisbos en Fabián Dobles (En el San Juan hay tiburón), José León Sánchez (La isla de los hombres solos y La Colina del Buey) y Gerardo César Hurtado (El libro brujo). Hay que enfatizar, eso sí, la novelística de la Región Norte, como la de Adriano Corrales Arias (Los ojos del antifaz, Balalaika en clave de son, Lina) y la de Álvaro Vega Sánchez (la novela Emma), así como parte de la cuentística de Gerardo Campos Gamboa y, naturalmente, en la narrativa del mismo Rodríguez Barrientos.

En La sed de los días las acciones transcurren en el río San Carlos y sus riberas, el río San Juan, límite fronterizo, y el gran lago Cocibolca de Nicaragua hasta el Caribe nicaragüense. Pero, además, ya hemos asistido a San Isidro de Coronado y alrededores, Grecia, Villa Quesada y la "bajura" sancarleña, así como a la zona de los Santos durante la Guerra Civil, Puntarenas y el Pacífico
Sur, San José, por supuesto, y más tarde a Caracas y el oriente venezolano. Hay descripciones intensas que se avienen muy bien con el estado de ánimo del personaje, su psicología y el trepidar de las acciones:

Arranqué el bote y lo conduje durante algún tiempo por la margen derecha del río, cuya cobertura boscosa era más densa que la de la ribera opuesta; de esta forma podía ocultarme mejor de las miradas ajenas, caso de haberlas atisbando por ahí. De todos modos la noche era bastante oscura y solo iluminada a trechos en el cielo por el resplandor de las estrellas y de la luna en cuarto menguante. Para mi fortuna, desde hacía varios minutos había dejado de llover. Yo conocía bien el trayecto, casi podía llevar la lancha con los ojos cerrados. No obstante, tenía los ojos muy abiertos y observaba cuidadosamente el cauce del San Carlos, crecido a causa de los recientes aguaceros. (La sed de los dias, 2017, pp. 203-204).

Por lo anterior, se podría afirmar que esta obra es una novela de frontera, o fronteriza, ya no solo por la geografía entre dos naciones, Nicaragua y Costa Rica, sino porque se adentra más allá de las fronteras agrícolas y socioculturales del país en una época de conformación de un nuevo Estado nacional, a partir de un singular y renovado pacto social, conocido como la Segunda República. Por otra parte, las fronteras temporales 
y psicológicas se cruzan en un estilo de narración muy apropiado para tal efecto. Es, por demás, una novela de formación, ya que antes hemos conocido parte de la infancia, adolescencia y juventud del personaje principal, junto a artesanos y obreros anarquistas y militantes comunistas, así como los primeros escarceos de amor de Teodoro, el cual, por su vida errante, debe conformarse con variedad de mujeres en toda suerte de prostíbulos o casas de citas.

A medida que se forja la conciencia sociopolítica e ideológica del personaje, se cimienta su cultura a través de viajes y profusas lecturas. Teodoro se convierte en un lector voraz y en un melómano; siempre encuentra maestros que lo orientan en sus pesquisas históricas, filosóficas, literarias y artísticas. En el viaje por la vida de este singular personaje vamos también tomándole el pulso a momentos importantes de la historia social del país, en diversas localidades y regiones (muchas de ellas, repito, inéditas en nuestra literatura), y a sus particularidades en cuanto a la conformación de fuerzas sociales y bloques políticos. Viajamos hasta la Venezuela del dictador Pérez Jiménez con su represión, crímenes y terrores, lo que le brinda una apertura en su cronotopo, de manera tal que la narración se internacionaliza y logra robustecer su verosimilitud histórica.
Por su parte, el sustrato de la novela nos coloca frente a disímiles identidades de eso que se ha dado en llamar "lo costarricense". Ya sin folclor y sin realismo socialista -sin tesis alguna que probar-, la novela transcurre con una verosimilitud sólida en cuanto a personajes, locaciones y peripecias, lo que provoca que sigamos interesados en su lectura y en el epílogo de la vida de Teodoro y sus seres queridos. La misma se torna más interesante e intensa, dado que está enmarcada en un período de la historia patria poco frecuentado por la literatura criolla y se atreve con momentos dramáticos y desconocidos para muchos posibles lectores, especialmente los jóvenes, lo que intensifica su valor literario.

\section{A modo de conclusiones}

Se ha realizado un breve recorrido por la joven literatura de la zona norte, cuyo centro de producción más sobresaliente es el cantón de San Carlos, específicamente su distrito central, Ciudad Quesada. Dentro de ese panorama, se ha acentuado la obra del escritor Francisco Rodríguez Barrientos, por considerársele un caso paradigmático ya no solo en la zona norte, sino en el país y más allá de la región centroamericana, dada la variedad de géneros y tópicos, así como su notable factura. La obra de Rodríguez Barrientos y sus fortalezas permiten aseverar que la misma no se queda en el plano regional, sino que, desde la 
periferia, irradia al resto del país, a Centroamérica y al resto de Hispanoamérica. La misma no se puede enmarcar dentro de las deformaciones y rezagos temporales o estructurales (folclor, primitivismo, naif, sub/subdesarrollo, etc.) de una supuesta "literatura nacional". Es una obra emergente que ha sido "combatida" por el "centro" a través del silencio, puesto que no ha sido incorporada como parte del canon, ni mucho menos. Así lo atestigua su novela La sed de los días, para no hablar de sus aforismos y ensayos, por ejemplo.

En esa perspectiva la pregunta final debería ser: ¿Quién decide qué es "literatura nacional" y/o "regional", y qué tipo de literatura debe escribirse, publicarse y leerse en la nación? Dicho de otro modo, ¿quiénes determinan el canon de una nación? Y para efectos de esta comunicación: ¿Es la obra de Francisco Rodríguez Barrientos una obra nacional o se queda en lo regional/marginal? En todo caso: ¿Cómo se plantean las diferencias, las identidades, el catálogo y los rezagos, o quiénes realmente hacen la diferencia a pesar de esas diferencias y de sus diversos cronotopos? Las réplicas posibles nos llevan a preguntas más concretas: de existir las literaturas regionales, ise expresan y se sustentan por el origen de sus enunciados (lugar de escritura y nacimiento del autor) o por sus temáticas y enfoques? ¿Es, en ese sentido, la novela La sed de los dias una novela regional de la zona norte porque su autor es sancarleño o por su temática? Puede ampliarse la consulta: la novela del mismo autor, Sombra errabunda (2018), de tópico enteramente urbano/ capitalino, ¿podría considerarse de la zona norte de acuerdo a la autoría?

Se puede inquirir más a modo de ejemplos: Limón blues (2002) y Limón reggae (2007), ¿son novelas de la región caribe costarricense aunque las escriba una mujer (Anacristina Rossi) que reside en el Valle Central? Más problemático aún, ¿pertenecen esas novelas a una supuesta literatura negra o afrolimonense si fueron escritas por una mujer "blanca"? O, Breve historia de todas las cosas (1975), novela escrita por el narrador colombiano Marco Tulio Aguilera Garramuño en San Isidro de El General, Pérez Zeledón, con temática y personajes de esa región, ¿es una novela perteneciente a la narrativa de la zona sur, si es que existe la narrativa de esa región? Más amplio aún: ¿Es una novela costarricense o colombiana? (Recibió el Premio Nacional de Novela Aquileo J. Echeverría el mismo año de su edición: Aguilera Garramuño se había nacionalizado como costarricense). Un ejemplo más: ¿Es el emblemático poema Ciudad Quesada (1962), del maestro nicaragüense José Coronel Urtecho, una pieza perteneciente a la literatura de San Carlos (de Costa Rica) y, por tanto, de la zona norte? El cuestionario da para más. La discusión puede y debe ampliarse; ese es, por cierto, el objetivo medular de este ensayo. 
Es claro entonces que "lo regional" o particular, imbricado en "lo nacional", implica una tensión entre prácticas residuales y prácticas emergentes: hay una disputa por la autoridad narrativa, por el poder simbólico. El discurso de la autoridad central genera su contingencia (su resistencia) porque ella misma, al enunciarlo, se coloca al descubierto como ideología. Así, la "literatura nacional", o la "cultura nacional" ("la nación”, el "Estado/nación”), pasan de ser un símbolo discursivo al síntoma de un malestar. Ese malestar se expresa de diferentes maneras y se arraiga en los márgenes como una forma de resistencia discursiva ante la autoridad (el canon) y sus relaciones de poder.

Para efectos de esta propuesta, queda claro que Francisco Rodríguez Barrientos, como intelectual y escritor de una región sociocultural como la zona norte, no se considera "periférico" en términos conceptuales y literarios (estéticos), mucho menos en términos sociopolíticos. No es un autor subalterno, aunque no se le reconozca como autor "nacional". Su producción literaria expresa un malestar con la cultura hegemónica (vallecentrista), su dispositivo y su canon, pues posee plena conciencia, en términos creativos, éticos y políticos, de esa ideología que intenta homogenizar a la sociedad para "hablar" en su nombre. La sed de los días (al igual que muchas de sus obras) por su amplio cronotopo, la verosimilitud de su trama y de sus personajes, así como por la temática históricosocial, entre otras particularidades, es una novela que lo expresa fehacientemente. La misma consigna espacios geográficos y socioculturales prácticamente ausentes en la literatura de este país centroamericano. En ese sentido, es una novela de frontera y de formación tanto en términos de su propuesta conceptual como en términos de su trama y de su argumento. La narración se torna más interesante e intensa en tanto se enmarca en un período de la historia patria poco frecuentado por la literatura crio1la (los hechos político-militares de los años cuarenta del siglo pasado) y se atreve con momentos dramáticos y desconocidos para muchos posibles lectores, especialmente jóvenes, lo que fortalece su propuesta literaria.

\section{Referencias bibliográficas}

Aguilera, G. M. (1975). Breve historia de todas las cosas. Buenos Aires: Ediciones la Flor.

Anderson, B. (1993). Comunidades imaginadas. Reflexiones sobre el origen y la difusión del nacionalismo. México: Fondo de Cultura Económica. 
Bhabha, H. (2010). Disemi Nación. Tiempo, narrativa y los márgenes de la nación moderna pp. 385-421. En Nación y narración. Entre la ilusión de una identidad y las diferencias culturales. Homi K. Bhabha (comp.), Buenos Aires: Siglo Veintiuno Editores.

Campos, G. G. (1998). Marisol sí sabe por qué te quiere, Ernesto. San José: EUNED.

Corrales, A. A. (1995). Tranvía negro. San José: Alambique.

Corrales, A. A. (1999). Los ojos del antifaz. San José: Ediciones Perro Azul.

Corrales, A. A. (2005). Balalaika en clave de son. San José: Editorial Costa Rica.

Corrales, A. A. (2015). Lina. San José: BBB producciones.

Dobles, F. (1967). En el San Juan hay tiburón. San José: Editorial L'Atelier.

González, L. M. (1979). Poesía para niños. San José: Departamento de Publicaciones. Ministerio de Cultura, Juventud y Deportes.
Hurtado, G. (2002). El libro brujo. San José: Editorial Costa Rica.

López, L. (2018). Otoño sin tabúes. San José: Mirambell.

Rodríguez, F. (1996). Sobrevivencia del agua. San José: Alambique.

Rojas, F. (1997). Avatares. Ciudad Quesada: Imprenta San Carlos.

Romano, C. (2017). La sed de los días. San José: BBB Producciones.

Romano, C. (2018). Sombra errabunda. San José: BBB Producciones.

Rossi, A. (2002). Limón blues. San José: Alfaguara.

Rossi, A. (2007). Limón reggae. San José: Editorial Legado.

Sánchez, J. (1972). La colina del buey. México, D.F.: Organización Editorial Novaro.

Sánchez, J. (1987). La isla de los hombres solos. México, D.F.: Grijalbo.

Vega, Á. (2012). Emma. San José: Lara Segura \& Asociados 